\title{
Using Basaltic Tuff for Decreasing the Growth Activity of Cyanobacteria
}

\author{
Larysa Cheban ${ }^{a^{*}}$, Mykhailo Marchenko ${ }^{b}$
}

\author{
Yuriy Fedkovych Chernivtsi National University, 2 Kotsjubynskyi St., Chernivtsi 58012, Ukraine \\ a*I.cheban@chnu.edu.ua, bmmm.biochemistry@gmail.com
}

Keywords: M. aeruginosa, M. pulverea, basaltic tuff, cyanobacterial biomass

\begin{abstract}
The atricle is devoted to the study of the cultivation of cyanobacteria Microcystis aeruginosa (Kützing) Kützing, Microcystis pulverea (H.C.Wood) Forti. in the presence of basalt tuff. The possibility of using basalt tuff as an adsorbing material for regulating the number of cyanobacteria and preventing toxic "water bloom" in fluid circuits.

The study analyzes the change in the biomass amount and the dynamics of the proportion of dead cyanobacteria in response to the presence of basalt tuff in the culture medium. It is noted that the use of basalt tuff leads to a decrease in the growth activity of cultures of Microcystis aeruginosa, Microcystis pulverea, manifested in an increase in the number of dead cells and slowdown the accumulation of cyanobacterial biomass. These effects are the result of a decrease in the amount of available nitrogen in the nutrient medium.
\end{abstract}

\section{Introduction}

The problems caused by the "water bloom" and the massive development of cyanobacteria and microalgae are again attracting the attention of researchers all over the world. The progressive spread of common species of cyanobacteria and microalgae is a consequence of the uncontrolled use of natural water resources, which is now observed in most regions of both Ukraine and the whole world. The negative consequences of this process are aggravated by the fact that in some cases the "bloom" is accompanied by the release of biologically active and toxic substances into the aquatic environment. These compounds are pyrogenic and toxic, they cause skin irritation and allergic reactions in both people and animals [1,2], and can also be fatal in the population. Toxins that are in the cells of cyanobacteria, after the destruction of these cells enter the aquatic environment. They are very stable, not destroyed by chlorination of water, and toxins are stored in dry cells [3-5]. The use of algaecidal preparations does not always make it possible to avoid the mass death of cyanobacteria and does not prevent the toxins from entering the aquatic environment.

Therefore, it is necessary to search for methods that allow regulating the number of cyanobacteria in the aquatic environment, while not allowing their mass reproduction and release of toxins into the environment. This can be avoided by filtration, water exchange, aeration, and adsorption methods [6-8]. The main thing when choosing a method is the ability to control the number of both vegetative cells and the spores of cyanobacteria. Unfortunately, most of these methods are cumbersome and expensive.

One of the alternative ways to prevent the massive development of cyanobacteria can be the use of adsorption methods. The need for materials with adsorbing properties puts forward a number of requirements relating to their technological efficiency, economic feasibility and biological activity. Adsorbing materials must have a high specific surface area, be non-toxic to invertebrates and fish and do not need complex sample preparation [9]. Promising adsorbing material with polyfunctional properties are basalt tuffs, which have found their application in various fields. Basalt tuffs are volcanogenic minerals that are structurally similar to zeolites in chemical composition. These are natural aluminosilicates, which in explored deposits are represented by igneous rocks and minerals. High chemical and thermal stability, significant deposits in the depths of Ukraine give reason to consider basalt tuff (BT) as a promising mineral raw material, and the near-surface tiff deposits make it possible to mine them in an open way [10,11].

It is known that tuff is a polyfunctional adsorbent and can be used to purify water from various types of contaminants. Basalt tuff, as a powerful natural sorbent, has a high selectivity of 
absorption and the ability to separate the size of ions and molecules of various substances, a sufficiently high mechanical and chemical resistance. In the course of its operation, it changes little of its physicochemical properties, retains a high ion-exchange selectivity to a variety of chemical elements [12].

The aim of the work was to assess the effect of basaltic tuff on monocultures of cyanobacteria Microcystis aeruginosa (Kützing) Kützing, Microcystis pulverea (H.C.Wood) Forti.

\section{Materials and Methods}

The studies were conducted using cultures of cyanobacteria Microcystis aeruginosa (Kützing) Kützing. and Microcystis pulverea (H.C.Wood) Forti. The original accumulative cultures were cultivated in a climatic room with a 16-hour photoperiod and a temperature of $24 \pm 2{ }^{\circ} \mathrm{C}$ on a modified Fitzgerald medium until the exponential growth phase. These cultures served as a source of material for studying the effect of basaltic tuff on the growth activity of cyanobacteria. Layer waste water from RAS [13] was used as a nutrient medium. All manipulations with cyanobacterial cultures were carried out in laminar boxing conditions.

We used samples of minerals obtained from the Polytske-2 field. Samples are characterized by the following composition: zeolites $35-40 \%$, montmorillonites $30-40 \%$, feldspar $10-15 \%$, silica $4-5 \%$, hematite $3-5 \%$ [14]. Basalt tuff was introduced into the nutrient medium in the range from 5 to $50 \mathrm{~g} / 1$ of medium. Concentrations were selected based on recommendations in the literature and previous developments of our laboratory.

The exposure of basalt tuff monocultures of M. aeruginosa and M. pulverea was 5 days. In the course of cultivation, the $\mathrm{pH}$ of the nutrient medium, the density of algoculture, biomass accumulation, the change in the number of dead cells, the change in the number of different forms of nitrogen in the nutrient medium were monitored and the toxicity coefficient of basalt tuff on cyanobacteria cells was calculated.

Determination of the $\mathrm{pH}$ of the nutrient medium was carried out by potentimetric $\mathrm{pH}$ measurement using a glass electrode (U-160 MU ion meter).

The accumulation of biomass was analyzed by changing the optical density of the culture at a wavelength of $750 \mathrm{~nm}$ on CaryWin UV 60 (Agilent, USA). In the future, we carried out calculations of dry biomass through the experimentally established coefficient $\mathrm{k}$ : ADB $=\mathrm{k} \times \mathrm{D} 750$ $(\mathrm{k}=\mathrm{g} / \mathrm{l} / \mathrm{u}$.opt. density) [15].

Suspension cultures were colored with vital dyes (methylene blue and neutral red - 1: 5000). Cell counting was performed using a Fuchs-Rosenthal camera and a Micromed XS-3300 trinocular microscope. The percentage of dead cells was calculated as a percentage of the total number of cells [16].

The amount of nitrate, nitrite and ammonium nitrogen was determined by standard methods. The basis of these methods is the ability of nitrogen-containing compounds with appropriate reagents to form colored products, which are subsequently detected on a spectrophotometer. The quality reagent for the determination of nitrate nitrogen is Rochelle salt, nitrite is Griess reagent, and ammonium is potassium tetraiodomercurate [17].

By the number of cells in the cyanobacteria culture, before and after exposure to basalt tuff, the coefficient of death of culture was calculated by the ratio of the number of dead cells to the total number of cells.

Statistical processing of the obtained results was performed using Microsoft Excel software. Differences in the results discussed in the work are likely at a significance level of $p \leq 0.05$ by the Student's criterion. Quantitative determinations were carried out in 3-fold repeatability. 


\section{Results and Discussion}

Under laboratory conditions, a situation of mass development of cyanobacteria was modeled. To this end, the cyanobacteria $M$. aeruginosa and $M$. pulverea were cultivated on Fitzgerald modified medium until the exponential growth phase was over. At this stage, monocultures were characterized by the number of cells in suspension at the level of $3 \times 106-5 \times 106$ cells $/ \mathrm{ml}$. Such a number of cells corresponds to the situation of uncontrolled mass development of cyanobacteria in natural waters with a high level of eutrophication [18,19].

Initially, the growth activity of the cultures was analyzed in terms of biomass accumulation. To determine the biomass its indirect study through an indicator of optical density of the culture was used. It has been established that the presence of basalt tuff in a nutrient medium leads to inhibition of the growth activity of both cultures of cyanobacteria (Fig. 1).

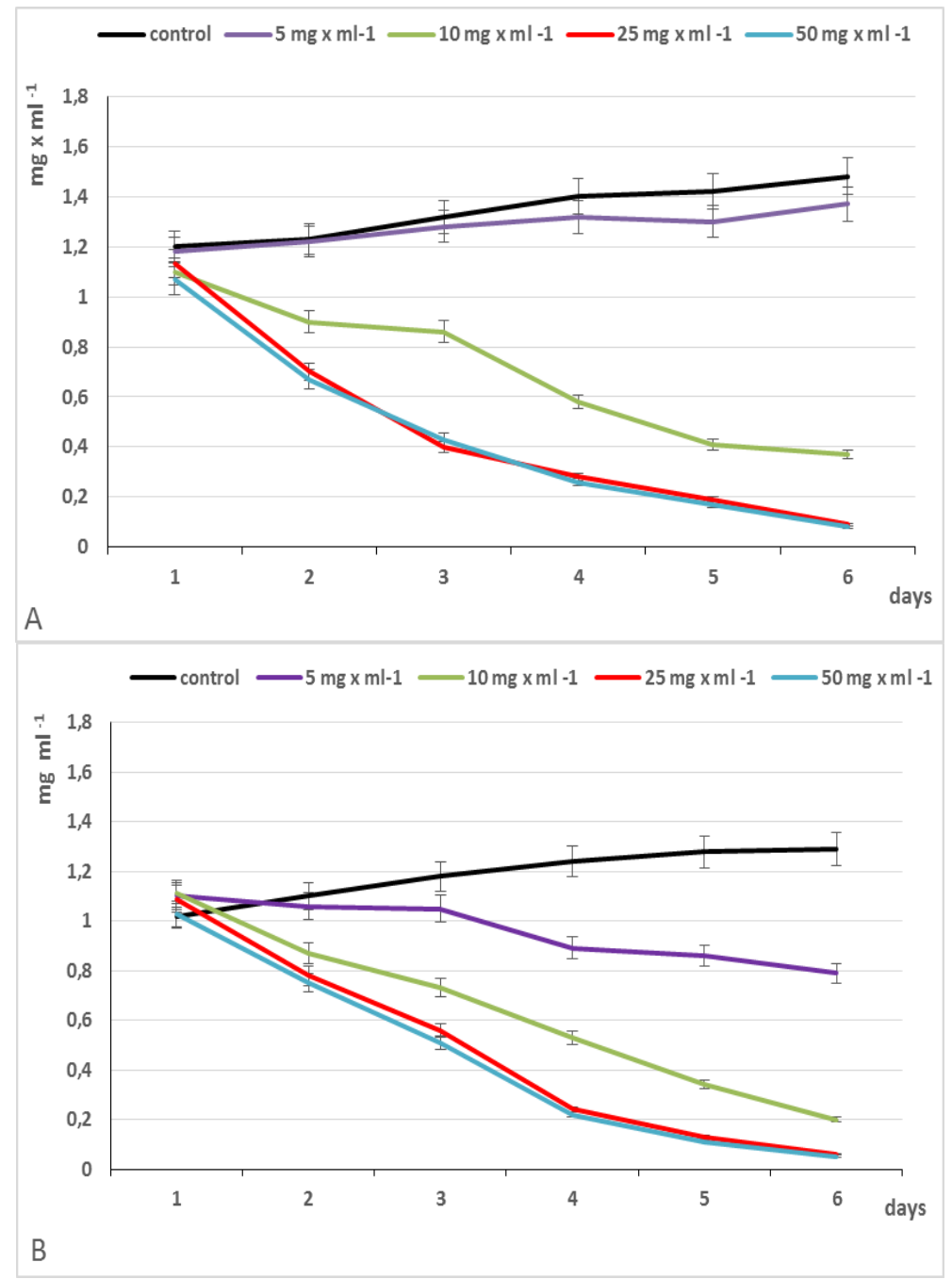

Fig. 1. Dynamics of biomass of cyanobacteria in the presence of basaltic tuff, where: A - $M$. aeruginosa, B - M. pulverea

At the same time, there was a difference in the reaction to the presence of tuff depending on the species of the culture and the concentration of tuff in the culture fluid. Thus, the initial culture of $M$. aeruginosa was characterized by a slightly higher growth activity than the culture of $M$. pulverea. This dependence persisted when the basalt tuff was introduced into the mediaum. The introduction of tuff at a concentration of $5 \mathrm{mg} / \mathrm{ml}$ had practically no effect on the accumulation of biomass, neither in the $M$. aeruginosa culture, nor in $M$. pulverea. Significant differences in the suppression of growth activity at this concentration were observed only starting from the third day of cultivation. An increase in the amount of basalt tuff in the nutrient medium when growing cyanobacteria affected the intensity of biomass accumulation in both of the studied cultures. 
A crucial decrease in the number of cells in the culture of $M$. aeruginosa and $M$. pulverea was achieved when basalt tuff was used in the amount of 25 and $50 \mathrm{mg} / \mathrm{ml}$ of the nutrient medium. Under these conditions, a sharp decrease in the amount of biomass starting from 24 hours of exposure was observed in both studied cultures of cyanobacteria. So, for the culture of $M$. aeruginosa, if $25 \mathrm{mg} / \mathrm{ml}$ of basaltic tuff is added to the medium, a 15-fold decrease in biomass was established, and for M. pulverea - 12-fold. The use of the adsorbent in the amount of $50 \mathrm{mg} / \mathrm{ml} \mathrm{did}$ not lead to a significant suppression of growth activity.

Later, using differential staining of culture cells, we conducted a study of the viability of cyanobacterial cultures exposed to basalt tuff. When the membranes of unicellular organisms are damaged, the dye easily penetrates the cells, their contents turn blue. Such cells are considered dead. In living cells, the dye is localized on the surface apparatus of the cell, and they turn red $(29,38)$. Against the background of the suppression of the biomass buildup, a gradual cell death was also observed in the culture of both cyanobacteria studied (Fig. 2). So, on the 5th day of exposure, the number of dead cells in the culture of $M$. aeruginosa increased 4.5 times with $10 \mathrm{mg} / \mathrm{ml}$ basalt tuff and 8.9 times with the maximum concentration of tuff in the nutrient medium. On the fifth day of incubation with $25 \mathrm{mg} / \mathrm{ml}$ basalt tuff, only about $10 \%$ of the cells in the M. aeruginosa culture remained viable.

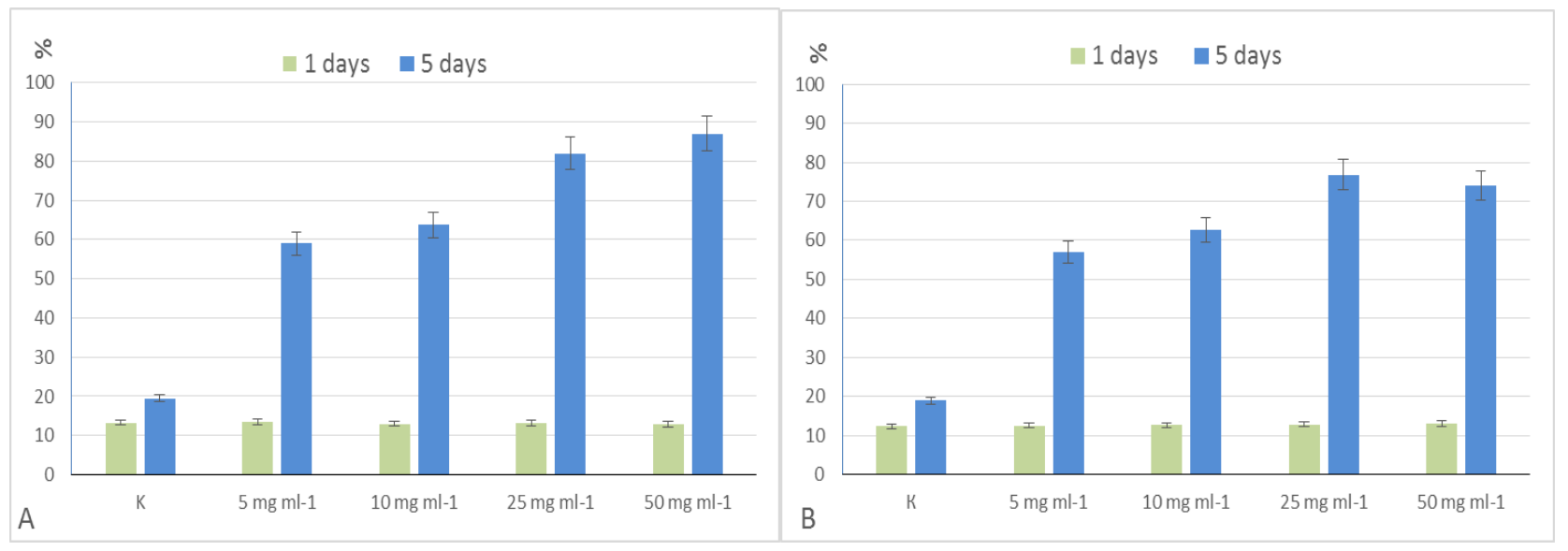

Fig. 2. The proportion of dead cells in cyanobacterial cultures in the presence of basalt tuff, where: A - M. aeruginosa, B - M. pulverea

Similar results, however somewhat less pronounced, were obtained for the M. pulverea culture: here, viability after incubation in the presence of $25 \mathrm{mg} / \mathrm{ml}$ basalt tuff was maintained in about $20 \%$ of the culture. The use of twice the amount of the studied adsorbent $(50 \mathrm{mg} / \mathrm{ml})$ did not lead to a significant increase in the proportion of dead cells in both the M. aeruginosa culture and the M. pulverea culture.

Reducing the proportion of living cells in culture allows us to predict that for a long time such a culture will adapt to the changed conditions of existence, its growth activity will remain low, which will avoid the mass development of cyanobacteria and, as a consequence, the release of toxins into the aquatic environment.

Based on the number of live and dead cells in the cyanobacteria culture, the coefficient of death of culture of basalt tuff was calculated (Table 1). As noted earlier, basalt tuff at a concentration of $5 \mathrm{mg} / \mathrm{ml}$ showed no toxic effect on cultures of the cyanobacteria studied. A slightly more pronounced toxic effect was when applying tuff at a concentration of $10 \mathrm{mg} / \mathrm{ml}$. And only an increase in concentration to 25 and $50 \mathrm{mg} / \mathrm{ml}$ led to a significant suppression of growth activity and toxicity. At the same time, no significant difference was found when using these two concentrations of the adsorbent. 
Table 1. Coefficient of death of culture of basalt tuff for cyanobacteria monocultures

\begin{tabular}{|c|c|c|}
\hline \multirow{2}{*}{$\begin{array}{c}\text { Concentration } \\
\text { of basalt tufts }\end{array}$} & \multicolumn{2}{|c|}{ Kd, \% } \\
\cline { 2 - 3 } & M. aeruginosa & M. pulverea \\
\hline $5 \mathrm{mg} \mathrm{ml}^{-1}$ & $10 \pm 0,9$ & $8 \pm 0,5$ \\
\hline $10 \mathrm{mg} \mathrm{m}^{-1}$ & $29 \pm 1,6$ & $24 \pm 1,3$ \\
\hline $25 \mathrm{mg} \mathrm{ml}^{-1}$ & $88 \pm 7,8$ & $79 \pm 6,9$ \\
\hline $50 \mathrm{mg} \mathrm{ml}^{-1}$ & $91 \pm 8,2$ & $80 \pm 8,5$ \\
\hline
\end{tabular}

According to some authors [8,20], low concentrations of adsorbents do not lead to inhibition of growth and development of cyanobacteria, but, on the contrary, can stimulate biomass growth due to the positive effect on the dynamics of nutrient medium indicators. Similar results were obtained when studying the effect on ammonium sulfate mixtures on cyanobacteria together with copper sulfate. Under such conditions, even in fairly high concentrations of chemical reagents, the number of cyanobacteria cells in the studied natural water decreased by only $50 \%$ with an exposure of 5 days.

Another factor of positive impact can be the ion-exchange properties of basalt tuffs [14]. Thus, in the study of the ion-exchange properties of tuff in water, the enrichment of the latter with bioactive elements was established. As a result of ion exchange, the content of iron, zinc, manganese, and potassium increased in water. As it is known, the main nutrient media for algae contain aqueous solutions of mineral salts, which provide algocultures with all the necessary elements. Their additional intake in small quantities may be the cause of a slight increase in biomass on the first days of cultivation of $M$. aeruginosa and $M$. pulverea when using basalt tuff in the amount of 5 and $10 \mathrm{mg} / \mathrm{ml}$.

The main limiting cultivation factor in the periodic system of microalgae is the depletion of the nutrient medium, the accumulation of target metabolites and metabolic products, which inevitably leads to changes in the $\mathrm{pH}$ of the cultivation medium. The temperature and $\mathrm{pH}$ of the medium is one of the most important abiotic factors regulating the rate of accumulation of the biomass of cyanobacteria. For each organism, there are optimal indicators of temperature and $\mathrm{pH}$. The active response of the environment depends on the concentration of hydrogen, one of the most fundamental factors of life in its various manifestations. Resistance to changes in $\mathrm{pH}$ in different organisms is different; most cyanobacteria are characterized by a neutral or slightly alkaline reaction of the medium, the optimum $\mathrm{pH}$ is $7.2-7.5$ [16]. The acidity of the environment affects the stability of the components of the nutrient medium, their availability to cyanobacteria, especially the absorption of growth factors. For most algocultures, it is precisely $\mathrm{pH}$ changes that are the driving factor for the attenuation of growth activity during long-term cultivation. The low growth activity of the $M$. aeruginosa and $M$. pulverea cultures, which we noted when basalt tuffs were used, could be related precisely to abrupt $\mathrm{pH}$ changes. However, we did not observe a similar phenomenon during the incubation of both the studied cultures in the presence of tuff (Fig. 3). On the contrary, the use of tuff allowed to maintain the $\mathrm{pH}$ value of the medium within the recommended limits. At the same time, a positive result did not depend on the concentration of the material used and was not significantly different for both types of cyanobacteria. Most likely, the inhibition of the growth activity of these algocultures is not associated with changes in $\mathrm{pH}$. 


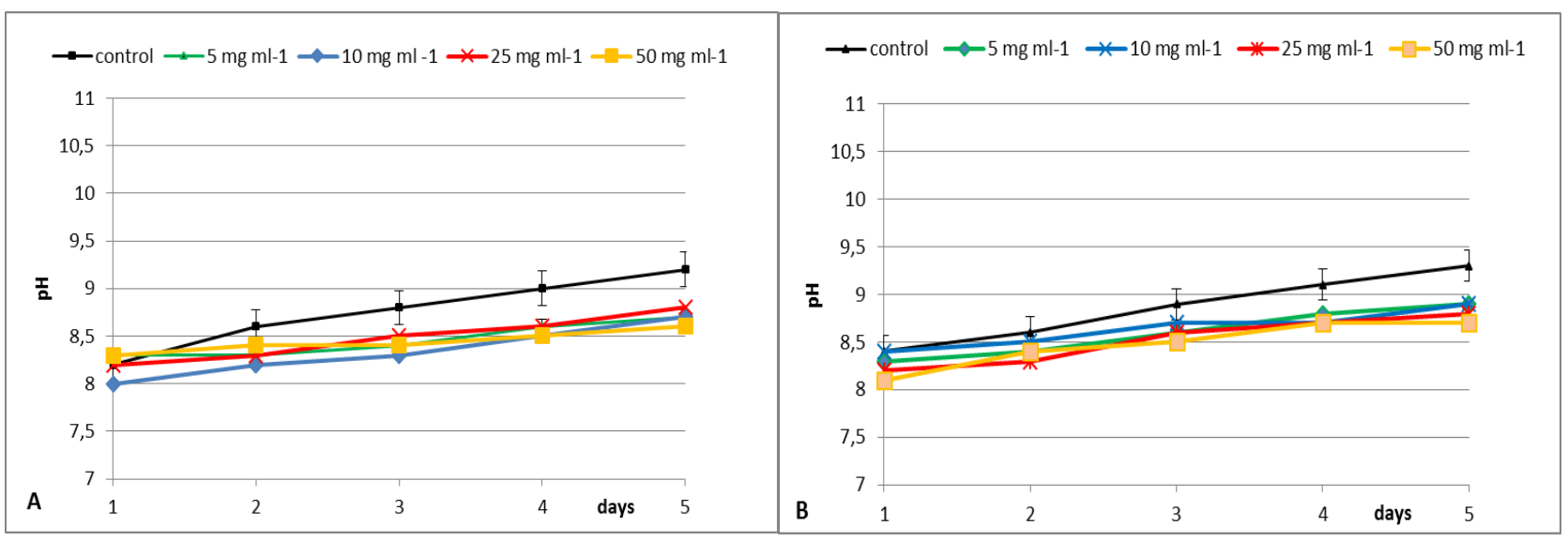

Fig. 3. Dynamics of $\mathrm{pH}$ in cyanobacterium cultures in the presence of basaltic tuff, where: A - M. aeruginosa, B - M. pulverea

Considering the results obtained, our next step was to study the effect of the presence of basalt tuff on indicators of the amount of various forms of nitrogen in the nutrient medium for cyanobacteria. Previously, we showed the possibility of cultivating cyanobacteria on wastewater from a hatchery of a closed water supply as a nutrient medium with a high content of nutrients [21]. In most cases, nutrient media form the basis of aqueous solutions of inorganic salts containing phosphorus, nitrogen, potassium, and other macro- and microelements. As is known, it is the amount and ratio of various forms of nitrogen and phosphorus that are decisive in the composition of the nutrient medium for algocultures [22]. The high content of nutrients due to excess nitrogen and phosphorus contained in fertilizer-rich wastewater from agricultural land, wastewater from livestock farms, fish ponds, allows using these wastewaters as alternative nutrient media for the cultivation of microalgae. Both sea and freshwater algae can absorb inorganic nitrogen compounds $\left(\mathrm{NO}_{3}{ }^{-}\right.$nitrates), nitrites $\left(\mathrm{NO}_{2}^{-}\right)$and ammonium $\left(\mathrm{NH}_{4}{ }^{+}\right)$. Regardless of the content in the water of certain forms of nitrogen, their assimilation and inclusion in the organic compounds of algal cells occurs only through the conversion of $\mathrm{NH}_{4}{ }^{+}$. This process has a two-stage character and is associated with an intracellular nitrate reductase complex. At the same time, free ammonia is poisonous, therefore, getting inside the cells, it does not accumulate, but is immediately used in biosynthetic processes [23]. The inclusion of ammonium ion in the process of biosynthesis of organic compounds occurs with the participation of the glutamine synthetase reaction. Under conditions of crucially reduced nitrogen content aquatic environment, the cells are nitrogendeficient, the process of utilization of $\mathrm{NO}_{3}{ }^{-}$and $\mathrm{NH}_{4}{ }^{+}$can occur at night, but in daylight its intensity is particularly high.

As one of the most important nutrients, nitrogen (mainly in the form of nitrates) significantly affects the biological productivity of aquatic ecosystems. In optimal concentrations, it causes increased production of phytoplankton, phytobenthos, and higher aquatic plants. The lack of mineral nitrogen leads to a decrease in the intensity of photosynthesis in plants.

We analyzed the amount of various forms of nitrogen in the nutrient medium when $M$. aeruginosa and $M$. pulverea were cultivated in the presence of basalt tuff (Fig. 4). It is noted that the introduction of basalt tuff into the nutrient medium reduces the amount of available nitrogen in various forms by $10-20 \%$, depending on the amount of material used. A decrease in the amount of nitrate nitrogen in the medium was observed when tuff was used in the amount of 25 and $50 \mathrm{mg} / \mathrm{ml}$. 

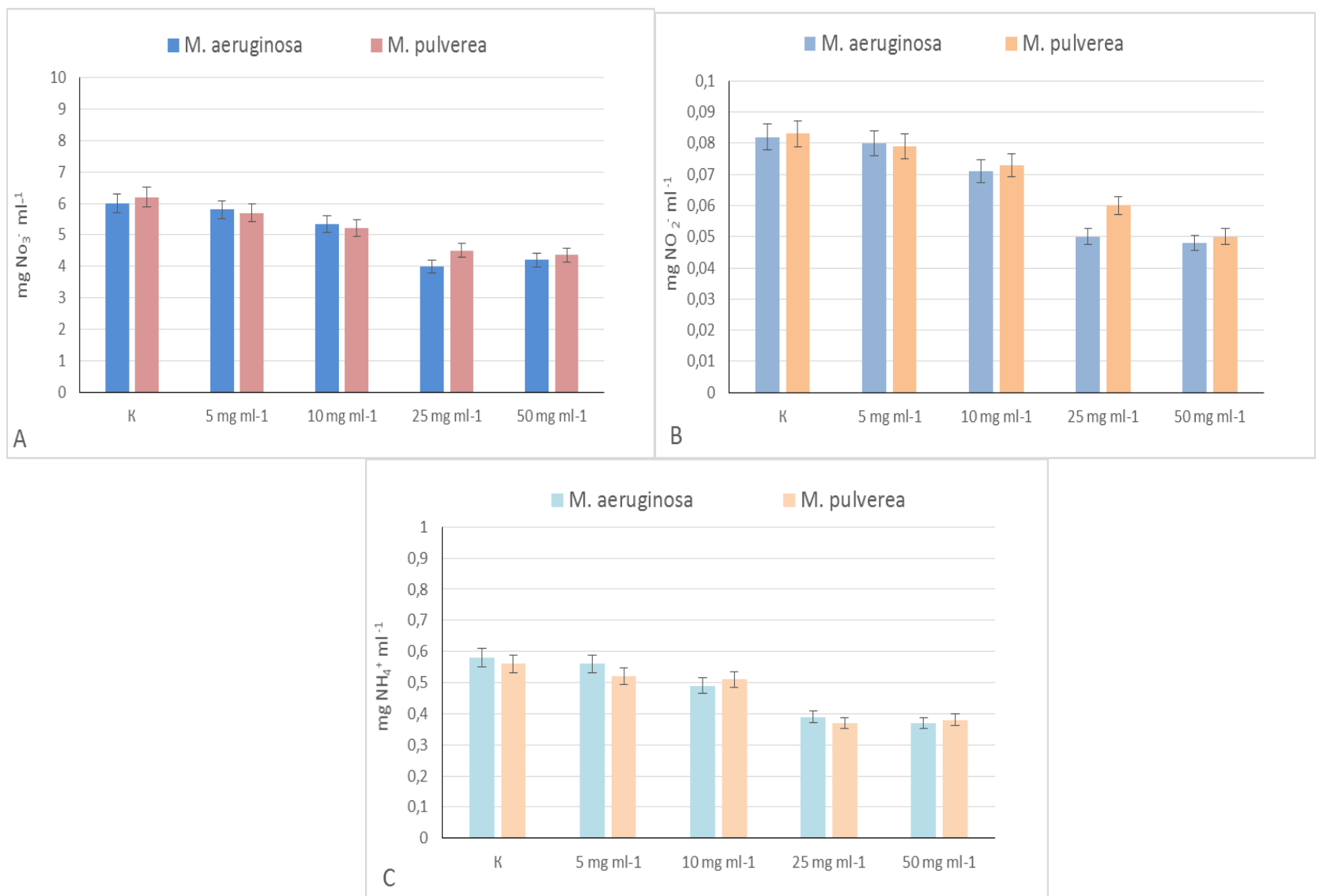

Fig. 4. Changing the amount of nitrate (A), nitrite (B) and ammonium (C) nitrogen in the nutrient medium in the presence of basaltic tuff

When using tuff in lower concentrations ( 5 and $10 \mathrm{mg} / \mathrm{ml}$ ), no significant changes in the amount of nitrate nitrogen were found. Similar trends were noted in the study of the amount of nitrite nitrogen in the nutrient medium during the cultivation of $M$. aeruginosa and M. pulverea. However, significant changes are noted already with the use of tuff at a concentration of $10 \mathrm{mg} / \mathrm{ml}$, while the use of the material under study in an amount of 25 and $50 \mathrm{mg} / \mathrm{ml}$ led to similar results. During 5 days of incubation, the amount of nitrite nitrogen in such conditions decreased by 1.7 times.

Similar patterns can be traced in the study of changes in the amount of ammonium nitrogen. During the incubation period of cyanobacteria with basalt tuff, about $35 \%$ of the total amount of $\mathrm{NH}_{4}{ }^{+}$was derived from the nutrient medium. It should be noted that ammonium and nitrate nitrogen under certain conditions are equivalent sources of nitrogen for plants. The predominant absorption of ammonium nitrogen occurs when $\mathrm{NH}_{4}{ }^{+}$is the only source of nitrogen $[16,17]$. The use of ammonium or nitrate nitrogen by plants depends on a number of factors, the most important of which are: the biological characteristics of the plant species, the availability of carbohydrates, the reaction of the environment, the presence of calcium, potassium and other nutrients, including trace elements.

In our opinion, it is the withdrawal of a sufficiently large amount of nitrogen-containing compounds from circulation that directly affects the growth activity of both cyanobacteria cultures studied. Since basalt tuff as a polyfunctional material actively adsorbs nitrogen-containing compounds, their amount is insufficient to meet the needs of algocultures.

So, using the example of two monocultures of cyanobacteria, we have shown the possibility of using basalt tuff as an adsorbing material for regulating the number of cyanobacteria and preventing toxic "water bloom" in aquatic systems. Such an approach will allow controlling mass outbreaks of cyanobacterial biomass accumulation both in controlled systems of the RAS type and in open water bodies. 


\section{Conclusions}

The inhibition of the growth activity of monocultures of cyanobacteria $M$. aeruginosa and $M$. pulverea in the presence of basalt tuff in the nutrient medium has been established. During the 5 days of incubation with $25 \mathrm{mg} / \mathrm{ml}$ basalt tuff, the amount of biomass in the M. aeruginosa culture decreased 15 times, and in the M. pulverea culture 12 times.

In the presence of basalt tuff in a nutrient medium against the background of a decrease in biomass, an increase in the number of dead cells in monocultures of cyanobacteria occurs. After incubation in the presence of $25 \mathrm{mg} / \mathrm{ml}$ basalt tuff, about $10 \%$ of the M. aeruginosa culture and $20 \%$ of the $M$. pulverea culture remained viable.

The introduction of basalt tuff into the nutrient medium leads to a decrease in the number of available nitrogen forms for cyanobacteria by $10-20 \%$, which results in the suppression of the growth activity of $M$. aeruginosa and $M$. pulverea.

Basalt tuff at a concentration of $25 \mathrm{mg} / \mathrm{ml}$ of the nutrient medium is recommended to be used as an adsorption material for regulating the number of cyanobacteria.

\section{Financing}

The work was carried out within the framework of the project "Application of biotechnological approaches in the artificial reproduction of native fish for the purpose of reintroduction" (2017-2019, State Registration No. 0117U001155).

\section{Conflict of interest}

There is no conflict of interest between authors in the publication of this paper.

\section{Acknowledgments}

The authors are grateful to I.M. Kobasa, Dr. Biol. Sc., Professor, Head of the Department of Chemical Analysis, Expertise and Food Safety, Chernivtsi Yury Fedkovich National University, for provided samples of basalt tuff and advising during the study.

\section{References}

[1] L. Blaha, B. Maršalek Microcystin production and toxicity of picocyanobacteria as a risk factor for drinking water treatment plants, Arch. Hydrobiol, 92 (2000) 95-108.

[2] L.N. Voloshko et al, Toxins of cyanobacteria (Cyanobacteria, Cyanophyta), Algology, 18 (2008) 3-20. (In Russian).

[3] G.A. Codd, L.F. Morrison Cyanobacterial toxins: risk management for health protection, Toxicology and Applied Pharmacology, 203 (2005) 264-272.

[4] PJ. Oberholster, A-M. Botha, JU. Grobbelaar Microcystis aeruginosa: source of toxic microcystins in drinking water, African Journal of Biotechnology, 3 (2004) 159-168.

[5] W. Hans, L. Paer, T.G. Otten Harmful Cyanobacterial Blooms: Causes, Consequences, and Controls, Microb Ecol., 65 (2013) 995- 1010.

[6] M. Abdel, M. Ibrahem, E. Gammal Potassium fertilizer inhibits the growth of Cyanobacteria (Microcystis aeruginosa) in fishpond, 8th International Symposium on Tilapia in Aquaculture, (2008) 127-139.

[7] G.A. Codd Cyanobacterial toxins, the perception of water quality, and the prioritisation of eutrophication control, Ecological engineering, 16 (2000) 51-60. 
[8] M. Li, P. N. Nkrumah, M. Xiao Biochemical composition of Microcystis aeruginosa related to specific growth rate: insight into the effects of abiotic factors, Inland Waters, 4 (2014) 357-362.

[9] R. Petrus et al, Technology of wastewater treatment using natural disperse sorbents, Chemical industry of Ukraine, 2 (2003) 20-22. (In Ukrainian).

[10] I.P. Burdeniuk et al, Natural Mineral - Basalt Tuff, promising to be harvested in industrial areas, biologia and medical, Clinical and Experimental Pathology, 12 (2013) 35-41. (In Ukrainian).

[11] V.V. Tsymbaliuk Investigation of various types of modification and catalytic properties of basalt tuff and study of its possibilities for wastewater treatment, Chemistry, physics and surface technology, 5 (2014) 335-348. (In Ukrainian).

[12] M. I. Hladyshev Biomanipulation as a tool for managing water quality in continental waters, Biol. inland waters, 2 (2001) 3-15. (In Russian).

[13] O.I. Khudyi et al, Recirculating aquaculture systems waste water as a medium for increase of phytoplankton and zooplankton biomass, International Letters of Natural Sciences, 54 (2016) 1-7.

[14] I.M. Kobasa, V.V. Tsymbaliuk, Natural mineral basaltic tuff: composition, lilac and use, Chernivtsi: Chernivtsi National University, 2016 - pp 200.

[15] R.H. Hevorhyz, S.H. Shchepachyov Methods of measuring the density of the suspension of lower phototrophs at the wavelength of light $750 \mathrm{~nm}$. - Sevastopol: Otdel byotekhnolohyy y fytoresursov YnBIuM NAN Ukraynu, 2008. - 10 s. (In Russian).

[16] T.V. Dohadyna et al, General and experimental algology, Kh. KhNU ymeny V.N. Karazyna, 2013 pp. 148. (In Russian).

[17] L. Vohnivenko, M. Yevtushenko, M. Shevryakov, Biochemistry aquatic - Kherson, Oldiplyus, 2009 - pp 536. (in Russian).

[18] B. Puschner, J.-F. Humbert Cyanobacterial proliferations in freshwater ecosystems, Veterinary Toxicology, (2007) 714-724.

[19] I.G. Sorokovykova Microcystin producing cyanobacteria in the waters of Russia, Belorusi, Ukraine, Chemistry for Sustainable Development, 21 (2013) 363-378. (In Russian).

[20] H. Oh et al, Microcystin Production by Microcystis aeruginosa in a Phosphorus-Limited Chemostat, Appl Environ Microbiol, 66 (2000) 176-179.

[21] T. V. Parshykova Application of micronutrients for optimization of mineral nutrition for industrial cultivation of microscopic algae, Physiology and biochemistry cult. Plants, 42 (2010) 403-413. (In Russian).

[22] E. Sanz-Luque et al, Understanding nitrate assimilation and its regulation in microalgae, Front Plant Sci, 6 (2015) 899-904.

[23] P.D. Klochenko et al, Features of assimilation of ammonium nitrogen by green and bluegreen algae, Hydrobiol. J., 38 (2002) 88-93. (In Russian). 